\title{
Fetomaternal outcome in patients with diabetes mellitus in pregnancy
}

\author{
Kaveri D. Shingala*, Sapana R. Shah, Rupa C. Vyas, Purvi M. Parikh
}

Department of Obstetrics and Gynecology, Smt. N.H.L. Municipal Medical College, Sheth V. S. General Hospital, Ellis Bridge, Ahmedabad, Gujarat, India

Received: 17 April 2019

Revised: 17 May 2019

Accepted: 30 May 2019

\section{*Correspondence:}

Dr. Kaveri D. Shingala,

E-mail: kaverishingala@gmail.com

Copyright: () the author(s), publisher and licensee Medip Academy. This is an open-access article distributed under the terms of the Creative Commons Attribution Non-Commercial License, which permits unrestricted non-commercial use, distribution, and reproduction in any medium, provided the original work is properly cited.

\section{ABSTRACT}

Background: Diabetes mellitus (DM) is defined as increased blood glucose level due to defect in insulin secretion, insulin action or both. Undiagnosed or inadequately treated diabetes mellitus during pregnancy can lead to significant maternal and fetal complications. The study was conducted to review feto-maternal outcome in pregnancy with diabetes and to plan management of pregnancy with diabetes and to study the modalities for treatment of DM in pregnancy.

Methods: A prospective case study was conducted from July 2015 to December 2018 at a tertiary care center. Study group used single step $75 \mathrm{gm}$ oral glucose tolerance test (OGTT) test recommended by WHO for GDM diagnosis.

Results: GDM (85\%) was more common than overt diabetes $(15 \%)$ and in younger age group $(53.75 \%)$ and Multiparous patients (18.2\%). Most of patients required insulin (81.2\%) for treatment of DM during pregnancy along with medical nutrition therapy and exercise. Most common association in this patient was hypertension (41\%). Rate of caesarean section $(60 \%)$ was more common. Average birth weight was of $>3.5 \mathrm{~kg}$, intrauterine death $(4.2 \%)$, preterm delivery $(14.2 \%)$ and admission to NICU were also common.

Conclusions: There was significant fetomaternal morbidity in patients with diabetes mellitus. Early diagnosis and treatment reduces the fetomaternal outcome.

Keywords: Feto maternal outcome, Glucose intolerance, Gestational diabetes mellitus, Glycemic control, Insulin, Oral glucose tolerance test

\section{INTRODUCTION}

Gestational diabetes mellitus (GDM) is defined as carbohydrate intolerance of variable severity with onset or first recognition during pregnancy (ACOG, 2017a). ${ }^{1}$ This definition applies whether or not insulin is used for treatment and includes some women with previously unrecognised overt diabetes. It doesn't exclude the possibility that unrecognised glucose intolerance may have began concomitantly with pregnancy. Pregnancy confers a state of insulin resistance and relatively diminished insulin levels that may predispose some women to develop diabetes and these is due to progressive rise in the levels of estrogen, progesterone, human placental lactogen, cortisol and prolactin as pregnancy advances, Many of these hormones are insulin antagonists which causes insulin resistance. ${ }^{2}$ Undiagnosed or inadequately treated GDM can lead to significant maternal and fetal complication. ${ }^{3}$ Women with GDM and their off springs are at increased risk of developing type 2 diabetes later in their life and recurrence of GDM is also seen in subsequent pregnancies. ${ }^{4}$ The incidence of DM in pregnancy is expected to increase to $20 \%$. Approximately $8 \%$ of all pregnancies are complicated by GDM. The prevalence may range from 1 to $14 \%$ of all pregnancies depending 
on the population studied and the diagnostic tests used5. Increasing levels of plasma glucose are associated with birth weight above the $90^{\text {th }}$ percentile, cord blood serum C-peptide level above 90th percentile, primary caesarean deliveries, neonatal hypoglycaemia. ${ }^{5,6}$ Risk factors for GDM includes history of macrosomia, strong family history of diabetes, obesity, undue weight gain, maternal age more than 25 years, persistent glycosuria, polycystic ovarian syndrome, significant past obstetrical history. ${ }^{6}$

Fetal complications likely to develop are macrosomia, IUD, malformation includes anencephaly, spina bifida, transposition of great vessels, VSD, renal agenesis, caudal regression syndrome, RDS, hypoglycemia, hypothermia, hyperbillirubinemia, hypocalcemia, hyperviscicity. ${ }^{7}$ Maternal complications includes a) Antepartam: abortion, preeclampsia, infection ,polyhydroamnios, maternal distress-due to polyamnios ,obesity macrosomic baby, b) Intrapartam: prolonged labourdue to big baby, shoulder dystocia, $\mathrm{PPH}$, increased incidence of caesarean section, c) Postpartam: Puerperal sepsis, increased maternal morbidity, diabetic retinopathy, diabetic nephropathy, diabetic ketoacidosis.

Improved outcome therefore depends on early diagnosis and good glycemic control. ${ }^{8}$

\section{METHODS}

A prospective study was conducted at a tertiary care center (V.S. General Hospital, Ahmedabad) over a period from July 2015 to December 2018. 80 patients with DM with pregnancy who were in criteria were studied for feto maternal outcome due to DM. Informed consent was taken from all the patients. Detailed history was taken including age, gestational age, history of still birth or pregnancy loss, family history of diabetes, past history of diabetes, obstetric history. Detailed examination was done. Various parameters noted were mode of delivery, fetal weight, maternal and neonatal complications, and neonatal intensive care admission.

\section{Inclusion criteria}

- Patients who had pregnancy with diabetes mellitus (gestational or overt)

- All the cases either registered or emergency.

\section{RESULTS}

Testing for GDM was done twice during ANC in all patients attending antenatal OPD. The $1^{\text {st }}$ testing was done during $1^{\text {st }}$ antenatal visit as early as possible in pregnancy. $2^{\text {nd }}$ testing was done during 24-28 weeks of pregnancy. If the 1 st test is negative there should be at least 4 weeks gap between the two tests. The test should be conducted for all pregnant women even if she comes late for antenatal visit for $1^{\text {st }}$ time. Single step testing using $75 \mathrm{gm}$. Glucose dissolving in approximately $300 \mathrm{ml}$ water given orally in fasting state and measuring plasma glucose 2 hours after ingestion. It considered Positive when $2 \mathrm{hr} P G \geq 140 \mathrm{mg} / \mathrm{dl}$ - managed as GDM as per guideline. Negative when 2 hours PG $<140 \mathrm{mg} / \mathrm{dl}-$ managed as normal patient and Once the diagnosis of diabetes mellitus was made in pregnant women, continued testing for glycemic control and diabetic complications were done for the rest of pregnancy. Data was collected, studied, analysed.

Table 1: Pregnancy outcome in study population.

\begin{tabular}{|c|c|c|c|}
\hline $\begin{array}{l}\text { Mode of } \\
\text { delivery }\end{array}$ & & No. $(80 \%)$ & Kalra Pet al \% \\
\hline Abortion & & $3(3.75 \%)$ & - \\
\hline \multirow{2}{*}{$\begin{array}{l}\text { Normal } \\
\text { delivery }\end{array}$} & $\begin{array}{l}\text { Preterm } \\
\text { delivery }\end{array}$ & $10(12.5 \%)$ & \multirow{2}{*}{21} \\
\hline & $\begin{array}{l}\text { Term } \\
\text { delivery }\end{array}$ & $19(23.7 \%)$ & \\
\hline $\begin{array}{l}\text { Caesarean } \\
\text { section }\end{array}$ & & $48(60 \%)$ & 79 \\
\hline
\end{tabular}

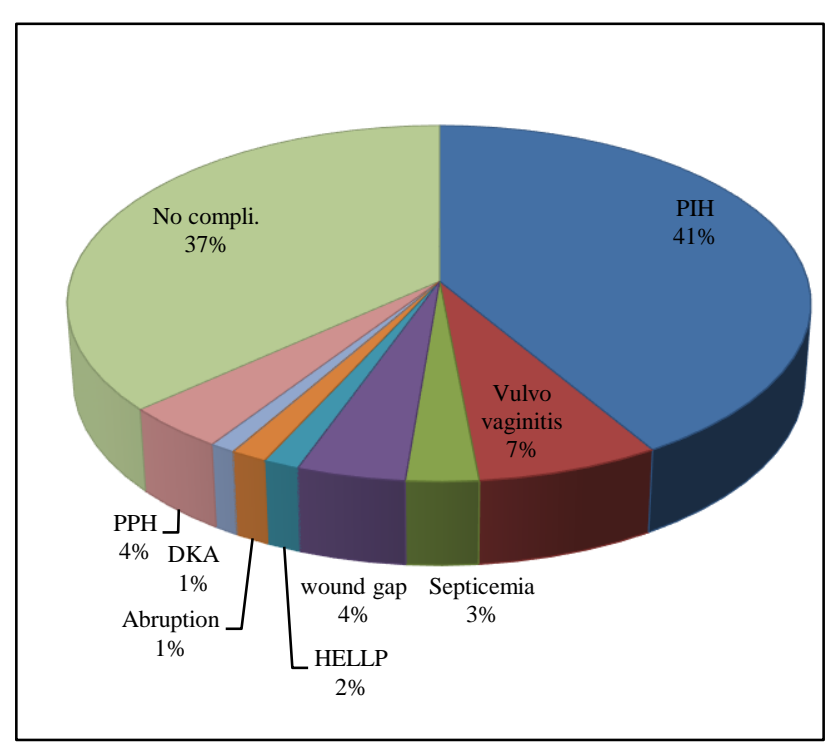

Figure 2: Maternal complications.

Statistical analysis showed out of 80 patients $68(85 \%)$ were diagnosed as GDM and $12(15 \%)$ were having overt diabetes mellitus. In present study $76.2 \%$ were registered patients and $23.7 \%$ were emergency patients. In this study maximum no. of patients were of younger, 20-29 years of age $(53.75 \%)$ and $46.25 \%$ were in age group of 30-39 years. Family history was present in $28.7 \%$ cases. Maximum patients $48(60 \%)$ were having HbA1c levels between 6.5 to $8 \%$ and 10 cases having $>8 \%$. Patients having adequate liqour, oligoamnios, polyamnios were in $36(45 \%), 14(17.5 \%), 24(30 \%)$ patients respectively on USG.

Out of 80 patients maximum had undergone Caesarean section as outcome (60\% patients) only 19 (23.7\%) patients were having normal term delivery (Table 1). Indications for caesarean section were CPD, PIH, or previous one or more caesarean section, big baby, 
unstable lie, fetal distress, ultered Doppler etc. Most complication noticed in diabetic patients was pregnancy induced hypertension (PIH) in $41.4 \%$ followed by Infectious which were in form of vulvo vaginitis and septicemia and least was diabetic ketoacidosis (1\%) (Figure 1). PIH was associated mostly with oligoamnios. Hypothyroidism was associated in $12.5 \%$ and preeclampsia in $36.2 \%$ patients in present study 65 $(81.2 \%)$ patients required medical management with insulin. Birth weight was normal in most newborn $(65 \%)$ and 11 had weight more than $4 \mathrm{~kg}$ (Table 2). Hyperbilirubinaemia (14.2\%) and Macrosomia (14.2\%) were maximum complications noticed and least was IUGR $(2.8 \%$ ) in present study (Figure 2). In present study one had anencephaly. Among 14 babies having birth weight $<2.5 \mathrm{~kg}, 2$ babies were IUGR due to PIH, 2 babies were IUD and rest were preterm.

Table 2: Distribution of birth weight of newborn in study population.

\begin{tabular}{|lll|}
\hline Birth Weight (kg) & No. (77)(\%) & Thomas B et al \% \\
\hline$\leq 2.5$ & $14(17.5 \%)$ & 40 \\
\hline $2.6-3.9$ & $52(65 \%)$ & 45.2 \\
\hline$\geq 4$ & $11(13.75 \%)$ & 8.1 \\
\hline
\end{tabular}

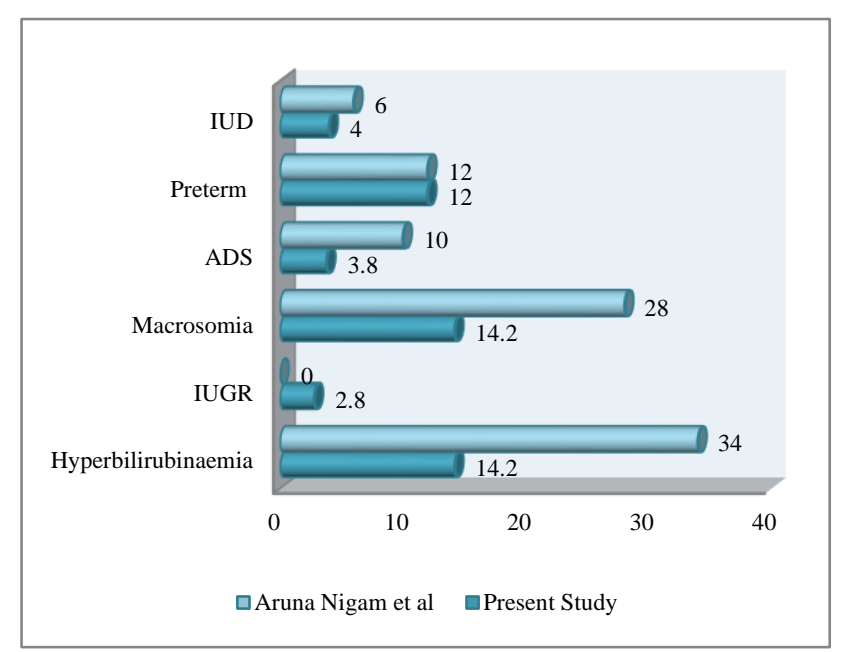

Figure 2: Fetal complications.

\section{DISCUSSION}

Over past years studies have strongly indicated that untreated diabetes during pregnancy is associated with higher rates of maternal morbidity and mortality. The purpose of screening and management of DM is to prevent stillbirth, congenital anomalies, recurrent abortion, pre-eclampsia, intra uterine death and decrease incidence of macrosomic babies hence reducing maternal and perinatal morbidity and mortality. The findings of the present study confirmed that DM patients are liable to have poor pregnancy outcomes.

In present study gestational diabetes was in $85 \%$ patients comparing with Wrong $\mathrm{T}$ et al, gestational diabetes was in $86.1 \%$ patients and $13.8 \%$ had overt diabetes. ${ }^{9}$ Registered patients had regular antenatal visits and good glycemic control. Emergency patients had poor glycemic control leading to more maternal and fetal complications than registered patients. Kalra $\mathrm{P}$ et al, showed rate of caesarean section was $79 \%$ comparing to this study it was $60 \%$ in diabetic patients. ${ }^{10}$ In present study $65 \%$ babies were having birth weight between $2.6-3.9 \mathrm{~kg}$ and $13.75 \%$ babies had weight $\geq 4 \mathrm{~kg}$. A study at Thomas B et al, shows $45.2 \%$ of babies are having birth weight between $2.6-3.9 \mathrm{~kg}$ and $8.1 \%$ babies had weight $\geq 4 \mathrm{~kg}$ indicating good glycemic control. ${ }^{11}$

Study from south India showed age $>25$ years is considered as a risk factor for GDM. ${ }^{12}$ In our study maximum no. of patients were of 20-29 years of age $(53.75 \%)$ and $46.25 \%$ were in age group of $30-39$ years. In present study family history were present in $28.7 \%$ cases, comparing with Di Cianni et al. reported that DM was more prevalent in women with positive family history. ${ }^{13}$ Yang et al. reported that pregnant women with a family history of diabetes in 1st degree relatives had 2 fold increased risk of DM as compared to those without positive family history of diabetes in 1 st degree relatives. ${ }^{14}$ In present study $30 \%$ were primigravida and $70 \%$ were multigravida. The higher rate among multigravida may be due to confounding effect of maternal age.

Several studies indicate a positive correlation between GDM and development of pre-eclampsia which was $41.4 \%$ in our study. Nigam A et al showed same result as present study of maximum complication in newborn baby was hyperbilirubinaemia (14.2\%) followed by macrosomia (14.2\%) (Table 4). Similarly, Macrosomia noted in $14.2 \%$ of the study group was comparable to the observations of Wahi $\mathrm{P}$ et al and Bener $\mathrm{AB}$ et al where macrosomia was seen in $16.2 \%$, and $10.3 \%$ respectively and in this study $4 \%$ IUD were noted compared to $6 \%$ in Nigam A et al. ${ }^{15}$

\section{CONCLUSION}

The study concluded that proportion of pregnancy with diabetes was less, probably because universal screening was not feasible due to certain constrains and probably because of improvement in medical and obstetric care at secondary level fewer patients were referred to tertiary care hospital. Pregnancy with diabetes was more common in younger age group. Rate of caesarean section was common in pregnancy with diabetes. IUD, preterm delivery, admission in NICU were common in diabetic patients. Birth weight $>3.5 \mathrm{~kg}$ were also common in diabetic patients. Prepregnancy counselling in patients with overt diabetes with good glycemic control can reduce complications. Educating patients about regular antenatal care and proper monitoring of blood glucose level are important measures to reduce maternal and fetal complications. Universal screening and management by team approach of obstetrician, diabetologist, anaesthetist, 
physician, neonatologist can reduce fetal-neonatalmaternal morbidity and mortality associated with pregnancy with diabetes.

Funding: No funding sources

Conflict of interest: None declared

Ethical approval: Not required

\section{REFERENCES}

1. Williams JW, Cunningham FG, Leveno KJ, Bloom SL, Spong CY, Dashe JS. Williams obstetrics. $25^{\text {th }}$ Edition. New York: McGrow - Hill; 2018:1107.

2. O'sullivan JB, Mahan CM. Criteria for the oral glucose tolerance test in pregnancy. Diabetes. 1964;13:278-85.

3. Landon MB, Mele L, Sc M, Spong CY, Carpenter MW, Ramin SM, et al. NIH Public Access. 2014;117:218-24.

4. Bellamy L, Casas JP, Hingorani AD, Williams D. Type 2 diabetes mellitus after gestational diabetes: a systematic review and meta-analysis. Lancet (London, England). 2009;373(9677):1773-9.

5. Report of the expert committee on the diagnosis and classification of diabetes mellitus. Diabetes Care. 2003;26 Suppl 1:S5-20.

6. Metzger BE, Lowe LP, Dyer AR, Trimble ER, Chaovarindr U, Coustan DR, et al. Hyperglycemia and adverse pregnancy outcomes. $\mathrm{N}$ Engl J Med. 2008;358(19):1991-2002.

7. Fareed P, Siraj F, Lone K. Fetomaternal outcome in women with gestational diabetes mellitus. Int J Res Med Sci. 2017;5(9):4151.

8. Crowther CA, Hiller JE, Moss JR, McPhee AJ, Jeffries WS. Effect of treatment of gestational diabetes mellitus on pregnancy outcome. N Engl J Med. 2005;352:2477-8.
9. Wong T, Ross GP, Jalaludin BB, Flack JR. The clinical significance of overt diabetes in pregnancy. Diabet Med. 2013;30(4):468-74.

10. Kalra P, Kachhwaha CP, Singh HV. Original article prevalence of gestational diabetes mellitus and its outcome in western Rajasthan. 2013;17(4):677-80.

11. Thomas B. The prevalence, risk factors, maternal and fetal outcomes in gestational diabetes mellitus. Int $\mathbf{J}$ Drug Develop Res. 2012;4(3).

12. Seshiah V, Balaji V, Balaji MS, Paneerselvam A, Arthi T, Thamizharasi M, et al. Prevalence of gestational diabetes mellitus in South India (Tamil $\mathrm{Nadu}$ ): a community based study. J Assoc Physicians India. 2008;56:329-33.

13. Di Cianni G, Volpe L, Lencioni C, Miccoli R, Cuccuru I, Ghio A, et al. Prevalence and risk factors for gestational diabetes assessed by universal screening. Diabetes Res Clin Pract. 2003;62(2):1317.

14. Clausen TD, Mathiesen ER, Hansen T, Pedersen O, Jensen DM, Lauenborg J, et al. High prevalence of type 2 diabetes and pre-diabetes in adult offspring of women with gestational diabetes mellitus or type 1 diabetes: the role of intrauterine hyperglycemia. Diabetes Care. 2008;31(2):340-6.

15. Saxena P, Tyagi S, Prakash A, Nigam A, Trivedi SS. Pregnancy outcome of women with gestational diabetes in a tertiary level hospital of north India. Indian J Community Med. 2011;36(2):120-3.

Cite this article as: Shingala KD, Shah SR, Vyas RC, Parikh PM. Fetomaternal outcome in patients with diabetes mellitus in pregnancy. Int J Reprod Contracept Obstet Gynecol 2019;8:2701-4. 